\title{
Harmful Algal Blooms
}

By Jennifer L. Graham

\section{What Are Harmful Algal Blooms (HABs)?}

Freshwater and marine harmful algal blooms (HABs) can occur anytime water use is impaired due to excessive accumulations of algae. HAB occurrence is affected by a complex set of physical, chemical, biological, hydrological, and meteorological conditions making it difficult to isolate specific causative environmental factors. Potential impairments include reduction in water quality, accumulation of malodorous scums in beach areas, algal production of toxins potent enough to poison both aquatic and terrestrial organisms, and algal production of taste-and-odor compounds that cause unpalatable drinking water and fish. HABs are a global problem, and toxic freshwater and (or) marine algae have been implicated in human and animal illness and death in over 45 countries worldwide and in at least 27 U.S. States (Yoo and others, 1995; Chorus and Bartram, 1999; Huisman and others, 2005).

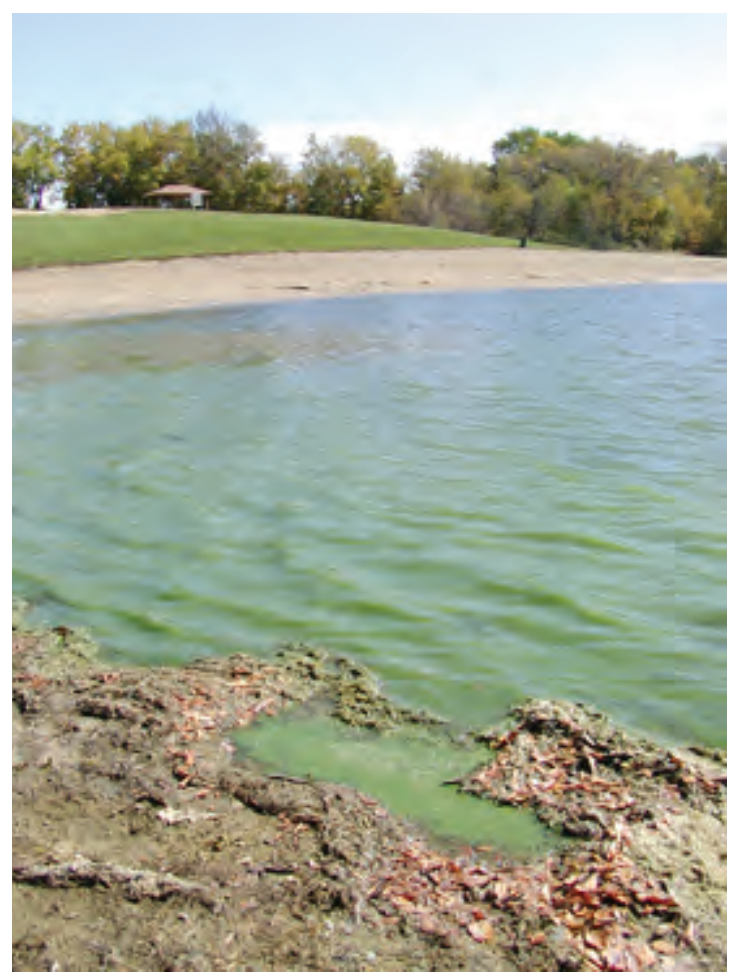

Harmful algal bloom in a Missouri reservoir used for drinking-water supply and recreation, October 2001.

\section{HABs Cause Public Health, Ecologic, and Economic Concerns in Both Freshwater and Marine Ecosystems}

\section{Public Health Concerns}

- Exposure to algal toxins may occur through consumption of tainted water, fish, or shellfish; recreational activities; or inhalation of aerosolized toxins.

- Algal toxins are known to cause illness immediately (hours to days) after exposure. In addition, several algal toxins are believed to be carcinogens or to promote tumor growth, although more research on the effects of long-term exposure is needed.

- Because of potential human-health risks, freshwater algal toxins are on the U.S. Environmental Protection Agency (2005) drinking-water contaminant candidate list, and fish and shellfish advisories are frequently posted in coastal areas.

\section{Ecologic Concerns}

- HABs may cause mortality of aquatic organisms because of low dissolved oxygen or algal toxins. Algal toxins also may cause mortality of terrestrial organisms using the water source.

- Long-term effects of persistent HABs on ecosystem structure and function are not well understood.

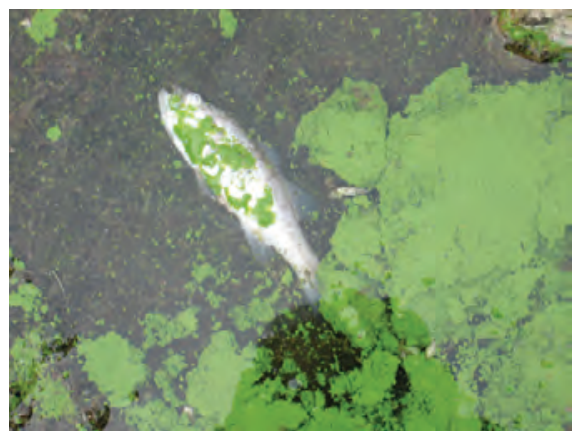

Harmful algal bloom in an lowa reservoir used for recreation, August 2006.

\section{Economic Concerns}

- Economic concerns associated with $\mathrm{HABs}$ include increased drinking-water treatment costs, loss of recreational revenue, loss of aquacultural and fisheries revenue, and livestock sickness or fatalities.

- Taste-and-odor compounds are of particular concern to drinking-water suppliers because of customer dissatisfaction with malodorous drinking water.

- Economic losses in the United States because of HABs during the last decade are estimated to be in excess of a billion dollars (U.S. Congress, 1998). 


\section{HAB Occurrence and Effects in the United States}

HABs have occurred in numerous aquatic ecosystems throughout the United States.

- During summer 2006 advisories were posted or beaches were closed at lakes and rivers in at least 12 States because algal toxin levels or toxin-producing algae were concentrated enough to be considered a threat to people and animals (fig. 1).

- Taste-and-odor problems in drinkingwater supplies were reported in at least 13 States during 2006 (fig. 1). Persistent taste-and-odor problems have led some utilities to make substantial changes in drinking-water treatment facilities. For example, Wichita,

Kansas, spent several million dollars to install ozone technology in its drinking-water treatment facility with the specific aim of decreasing tastes and odors in finished drinking water caused by algal blooms in the supply reservoir (instances documented from various media, oral, and Web sources on file with author).
- Approximately 30 reported cases of human poisoning by marine toxins are reported in the United States each year (Center for Disease Control, 2006). The actual number of cases may be greater because many algaltoxin-related illnesses go undiagnosed. Similar data are not available for freshwater algal toxins, although there are numerous documented cases of illness after exposure.

Figure 1. Anecdotal reports of the occurrence of taste-andodor and toxinproducing harmful algal blooms in the United States during 2006. Map data were gathered from news reports and are not all inclusive.
- There have been numerous documented cases of wildlife and domestic animal deaths associated with freshwater and marine algal toxins. For example, in summer 2006 there were documented dog deaths in Missouri and Nebraska and manatee deaths in Florida.

\section{EXPLANATION}

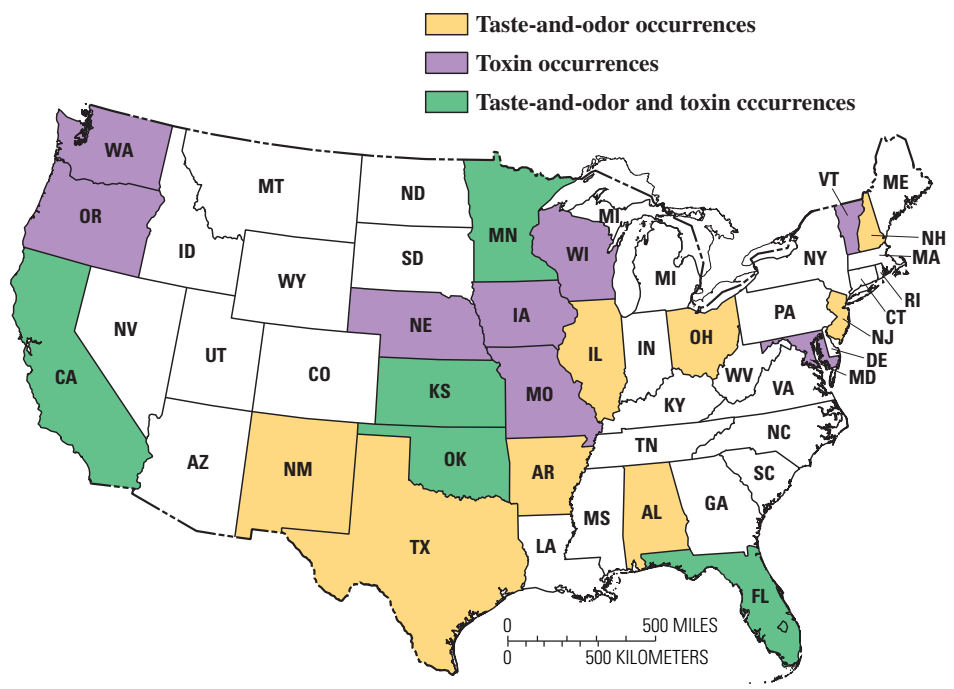

\section{Research Needs}

The U.S. Geological Survey (USGS) is engaged in HAB research throughout the United States. HAB study is an active area of developing research, but $\mathrm{HAB}$ research to date has emphasized marine ecosystems. There is a need for comparable work in freshwater systems.

- The occurrence of HABs, particularly those producing toxins or taste-and- odor compounds, is not well documented in the United States.

- Reliable analytical techniques for the analysis of toxins, taste-and-odor compounds, and algal identification and enumeration are required.

- Long-term studies in individual lakes, reservoirs, and rivers are needed to identify the environmental factors driving $\mathrm{HAB}$ formation and to docu-

\section{References Cited}

Center for Disease Control, 2006, Marine toxins frequently asked questions: Information available on the Web, accessed November 21, 2006, at http://www.cdc. gov/ncidod/dbmd/diseaseinfo/marine toxins_g.htm\#howcommon

Chorus, I., and Bartram, J., eds., 1999, Toxic cyanobacteria in water: New York, E\&FN Spon, $416 \mathrm{p}$.

Huisman, J., Matthijs, H.C.P., and Visser, P.M., eds., 2005, Harmful cyanobacteria: The Netherlands, Springer, 241 p.
U.S. Congress, 1998, Harmful algal bloom and hypoxia research and control act of 1998: Public Law No. 105-383, 16 USC 1451 note.

U.S. Environmental Protection Agency, 2005, The drinking water contaminant candidate list: Office of Water (4607M), EPA 815-F-05-001, 6 p.

Yoo, R.S., Carmichael, W.W., Hoehn, R.C., and Hrudey, S.E., 1995, Cyanobacterial (blue-green algal) toxins-a resource guide: Denver, Colorado, American Water Works Association Research Foundation, 229 p. ment the effect of changing environmental conditions on HAB occurrence.

- The development of methods for early detection and predictive models would allow resource managers time to respond more effectively to potentially harmful conditions.

For additional information visit the USGS Web site at:

http://ks.water.usgs.gov/Kansas/studies/ qw/cyanobacteria/

or contact:

U.S. Geological Survey

Director, Kansas Water Science Center 4821 Quail Crest Place Lawrence, Kansas 66049-3839

(785) 842-9909 or E-mail: dc_ks.usgs.gov 